\title{
Evaluation of Clinical and Chemical Profile of Patients with Urolithiasis in Pune, India
}

\author{
Dr. Suhas V. Taralekar ${ }^{1}$, Dr. Nidhi Sharma ${ }^{2}$ \\ Department of Surgery, Bharati Vidyapeeth Deemed University Medical College, Dhankawadi, Pune - 411043 Maharashtra, India
}

\begin{abstract}
Kidney stones are raising due to rapid industrialization. Stone formation is usually a result of urinary super saturation with the group of biominerals. We have evaluated clinical profile of patient with urolithiasis and analyse chemical composition of stone. We had studied 70 urolithiasis patients at department of general surgery, Bharati Vidyapeeth University Medical College, in Pune city.A male to female's ratio was 1.33:1. Most of patients had pain in left lumbar region (n=33, 47.14\%). Radiating back pain to back and groin was observed in 49 patients. Haematuria was the commonest problem in patients $(n=38,54.29 \%)$. The most of patients were drinking tap water $(n=53,75.71 \%)$. Maximum number of patient were reported for radio opaque shadow in left kidney (n=21, 30\%) and then right kidney ( $n=15,21.43 \%)$. We reported high level of serum creatinine, calcium, and phosphorus level than the normal range of parameters. Acinetobacter, Enterococccus species, EscherichiaColi, Gram negative bacilli, Klebsiellapneumonia, Pseudomonas species and Trichosporon species were found in few patients. Calcium oxalate monohydrate content was found $63.99 \pm 16.05 \%$. Calcium dihydrate $(44.55 \pm 6.105 \%)$, ammonium urate $(28.24 \pm 10.74 \%)$ and calcium phosphate $(47.81 \pm 16.63 \%)$ were also present in the stone. Dicalciumphosphtate was present in 9 stones and carbon apatite was present in 10 stones. Our study shows the current status of chemical composition of stones in urolithiasis patients. It is important to know the chemical composition of stone as it is useful in advising people for taking preventive measures for reducing the risk of prevalence and recurrence of stone.
\end{abstract}

Keywords: Stone, Urolithiasis, Calcium, Biominerals

\section{Introduction}

Urolithiasis is the formation of calculi (urinary stones), which are located anywhere in the urinary system. Kidneys were mostly affected as compared to ureter and bladder[1]. Kidney stones typically leave the body by passage in the urine stream, and many stones are formed and passed without causing symptoms. If stones grow to sufficient size (usually at least $3 \mathrm{~mm}(0.12 \mathrm{in})$ ) they can cause obstruction of the ureter. This leads to pain, a condition called renal colic,most commonly felt in the flank (the area between the ribs and hip), lower abdomen, and groin.

It is estimated that at least $10 \%$ of the population in the industrialized part of the world is affected by urinary tract stone disease. Kidney stones are common in industrialized nations with an annual incidence of $0.5 \%$ to $1.1 \%$. Life-time risk of urolithiasis varies from 1-5\% in Asia, 5-9\% Europe, $10-15 \%$ USA and $20-25 \%$ middle-east; lowest prevalence is reported from Greenland and Japan[2].The incidence of urolithiasis is fairly high in South East Asia including several regions of India. In India, upper and lower urinary tract stones occur frequently but the incidence shows wide regional variation. The prevalence of urolithiasis is as high as $7.6 \%$ in Satpura part of Maharashtra[3]. A high and progressively increasing incidence of urolithiasis in Udaipur and some other parts of Rajasthan in the western part of India\{Pendse, 1986 \#49\}. The incidence of renal calculi is comparatively low in the southern part of country compared to other parts.

Urinary stones belong to the group of biominerals. These stones are generally associated with high concentration of calcium in the blood or urine. Many studies from India have also documented that calcium oxalate forms the major constituent of renal calculi disease in India. Renal calculi are formed when the urine is supersaturated with salt and minerals such as calcium, ammonium magnesium phosphate, uric acid and cystine. Most renal calculi contain calcium, usually in the form of calcium oxalate $\left(\mathrm{CaC}_{2} \mathrm{O}_{4}\right)$ and often mixed with calcium phosphate $\left(\mathrm{CaPO}_{4}\right)$. High incidence of calcium oxalate stones have been attributed to major consumption of cereals like millet, which are high in calcium and phosphate, beside factors like lack of animal proteins and increased consumption of oxalate rich vegetables.Dietary factors that increase the risk of stone formation include low fluid intake and high dietary intake of animal protein, sodium, refined sugars, fructose [4] and high fructose corn syrup[5], oxalate[6], grape fruit juice, apple juice, and cola drinks[7]. Stone formation commonly occur due to inadequate urinary drainage, foreign bodies in urinary tract, microbial infections, diet with excess oxalates and calcium, vitamin abnormalities like vitamin A deficiencies, excess vitamin $\mathrm{D}$, and metabolic diseases like hyperthyroidism, cystinuria, gout, intestinal dysfunction etc.[7]

Till date, various cities of india has been studied for urolithiasis such as in Manipur[8], Udaipur[9], Bombay[10], Vijayawada[11], Dhule[3], Karad[12], Patiala[13], Aurangabad[14].The observations strongly suggest the multifactorial etiology of stone disease in this regions such as imbalanced nutrition and urinary tract infection. Dietary habits revealed principal dependence on cereals, lack of animal proteins, consumption of oxalate rich vegetables and widespread consumption of tea. Majority patients belonged to the lower-middle or poor income groups[3] having a cereal based diet with minimal or poor protein intake[15]. Interestingly, the prevalence of bladder stones (BSF) was lower than that of upper urinary tract stones (UUTSF) which suggests the possibility of involvement of environmental pollution[10]. Urinary tract infection was present in $63.7 \%$ of the cases[8].

Many studies from India have also documented that calcium oxalate forms the major constituent of renal calculi disease 


\section{International Journal of Science and Research (IJSR) \\ ISSN (Online): 2319-7064 \\ Index Copernicus Value (2013): 6.14 | Impact Factor (2015): 6.391}

in India. The chemical analysis of urolithiasis showed that all the assessed stones were of mixed heterogeneous type, Magnesium Ammonium Phosphate (71.2\%), Calcium Oxalate (68.8\%), Calcium Carbonate (64.0\%), Urate (44.8\%), Cystine (12.8\%), Xanthine (2.4\%) and Fibrin (1.6\%)[10, 12, 13, 16]. Magnesium ammonium phosphate was present in many stones. The common constituents of stones were calcium (98.7\%), oxalate (87\%), phosphate (84.4\%) and uric acid (76.6\%)[15]. Urinary stones from endemic patients had higher fluoride, oxalate and calcium levels than those from non-endemic patients[17]. Renal calculi are formed when the urine is supersaturated with salt and minerals such as calcium, ammonium magnesium phosphate, uric acid and cysteine [18]. Most renal calculi contain calcium, usually in the form of calcium oxalate $\left(\mathrm{CaC}_{2} \mathrm{O}_{4}\right)$ and often mixed with calcium phosphate $\left(\mathrm{CaPO}_{4}\right)[18,19]$. Higher levels of urinary calcium andserum calcium was found in patients with urolithiasis $[14,20]$.

With its multi factorial etiology and high rate of recurrences, urinary tract stone disease provides a medical challenge. It is important to know the chemical composition of stone as it is useful in advising people for taking preventive measures for reducing the risk of prevalence and recurrence can be considerably reduced by suitable reforms in diet and treatment regimen. We have evaluated clinical profile of patient with urolithiasis and analyse chemical composition of stone. We observe that in Pune city, many families have member afflicted with urolithiasis.

\section{Material and Methods}

A prospective randomized study was conducted at Bharati Vidyapeeth university medical college and hospital, Pune from August 2013 to August 2015. Seventy patients presenting with various symptoms of urolithiasis were included in this study. Were studied. The bottom stay of this research was to evaluate clinical profile of patient with urolithiasis and analyse chemical composition of stone. Ethical clearance was obtained from the institutional ethics committee.Inclusion criteria was patients with urolithiasis who were surgically treated.Exclusion criteria was patients with urolithiasis treated withconservative/medical management.

In the history of patients with urolithiasis importance has to be laid upon pain in abdomen, radiating to back /groin, haematuria, burning micturition, increase frequency of urination, type of drinking water. Blood and urine samples of patients were collected and sent for various investigation such as urine routine, urinary $\mathrm{pH}$, urineculture and sensitivity, urinary phosphorus, urinary calcium, uric acid, serum calcium, serum magnesium, serum phosphorus,serum uric acid, serum sodium, serum potassium and serum creatinine. X-ray KUB, USG abdomen pelvic, intravenous pyelography were done. After surgical removal of stone, stones were sent for chemical composition analysis.

\section{Results}

\section{Age distribution}

In the study, we had taken 70 patients with the urolithiasis. Maximum number of patients( $n=26,37.14 \%)$ observed in the sixth decade of their life. We found 16 patients in age 41 to 50 year, which represent $22.86 \%$ of studied patients.

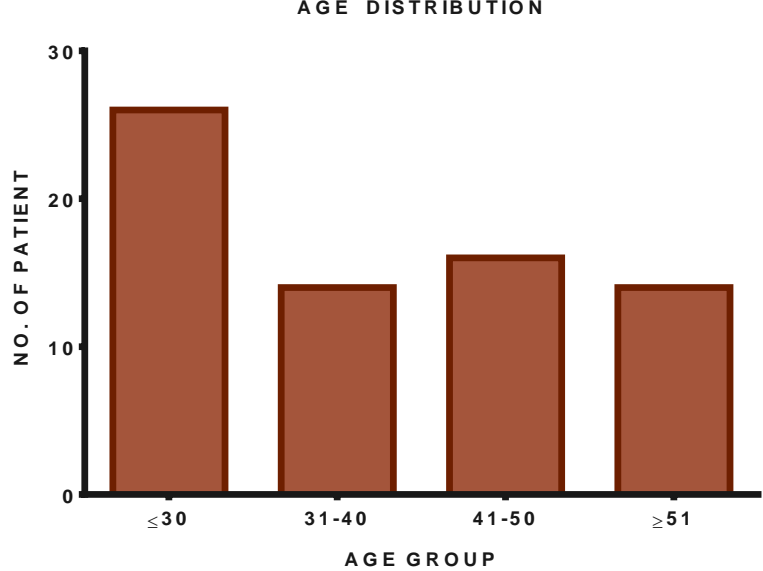

Figure 1: Patient age distribution

\section{Gender distribution}

Gender wise distribution of stones revealed a greater percentage of males $(n=41,58.57 \%)$. The incidence amongfemales was quite low $(n=29,41.43 \%)$. A male to female's ratio was 1.33:1.

Table 1: Gender Distribution

\begin{tabular}{|c|c|c|c|}
\hline Gender & No. of Patients & $(\%)$ & Male to female's ratio \\
\hline Male & 41 & 58.57 & $1.33: 1$ \\
\hline Female & 29 & 41.43 & \\
\hline
\end{tabular}

\section{Pain site in abdomen}

Pain and its location during urolithiasis is common and vary patient to patient according to position of stone. Most of patients had pain in left lumbar region $(n=33,47.14 \%)$ while 24 patients (34.29\%) patients had pain in right lumber region.

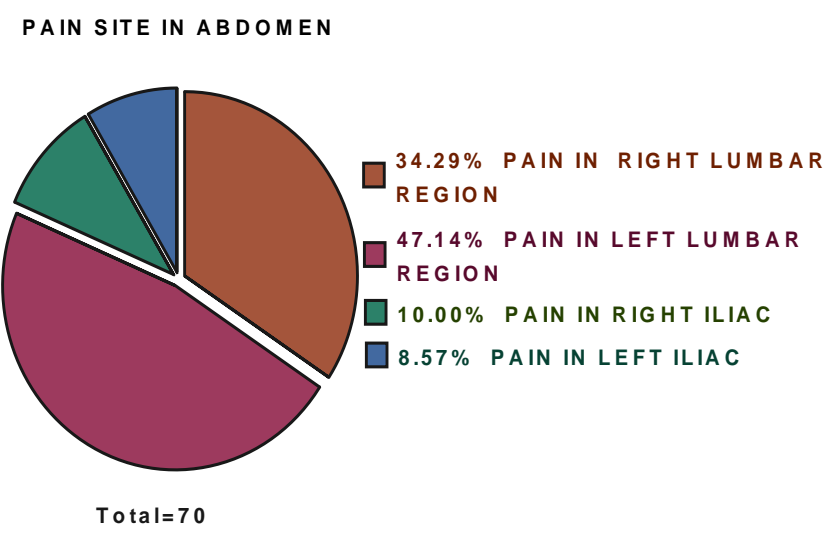

Figure 2: Pain site in abdomen.

\section{Pain radiating}

Radiating back pain to back and groin was observed in 49 patients, while only 21 patients were reported for absence of radiating back pain.

Table 2: Symptoms

\begin{tabular}{|c|c|c|}
\hline Symptoms & Pain Radiating To Back and Groin & $\%$ \\
\hline YES & 49 & 70.00 \\
\hline NO & 21 & 30.00 \\
\hline
\end{tabular}




\section{International Journal of Science and Research (IJSR) \\ ISSN (Online): 2319-7064}

Index Copernicus Value (2013): 6.14 | Impact Factor (2015): 6.391

\section{Urinary symptoms}

Symptoms like haematuria, burning micturition and increase frequency of urination was observed in the patient. Haematuria was the commonest problem in patients $(n=38,54.29 \%)$.

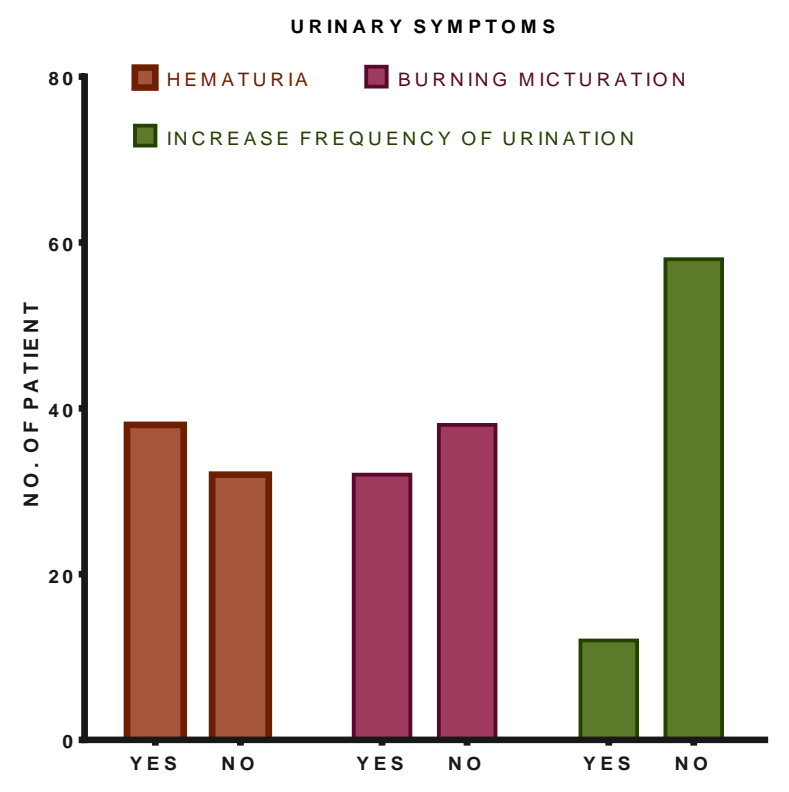

Figure 3: Urinary symptoms

\section{Type of drinking water}

We found that most of the patients were drinking tap water $(n=53,75.71 \%)$ while few patients were drinking bore well water ( $n=17,24.29 \%)$.

TYPE OF DRINKING WATER

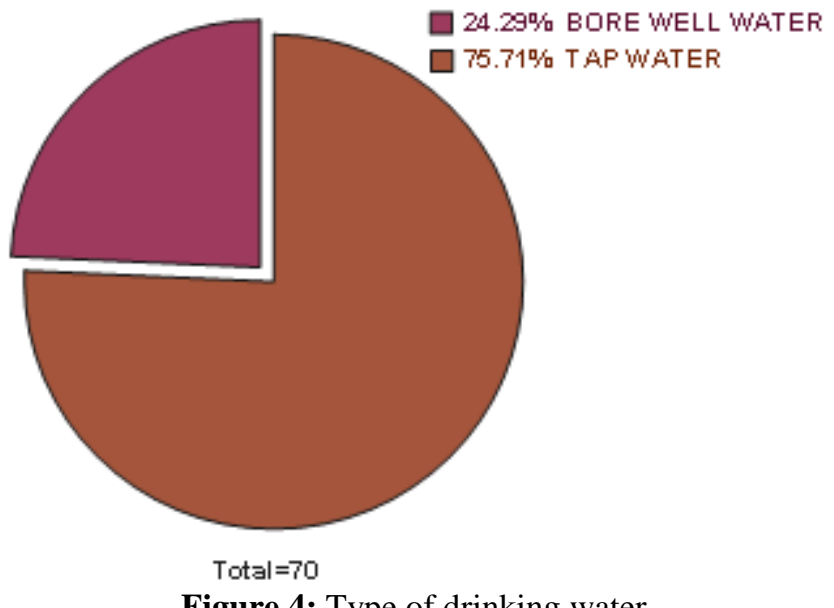

Figure 4: Type of drinking water

\section{Diet veg/non veg}

We recorded diet of patients as veg and non-veg. Veg patients were $(n=39,55.71 \%)$ and Non Veg. Patients were $(n=31,44.29 \%)$.

Table 3: Diet

\begin{tabular}{|c|c|c|}
\hline DIET & No. Of Patients & $\%$ \\
\hline VEG. & 39 & 55.71 \\
\hline NON VEG. & 31 & 44.29 \\
\hline
\end{tabular}

Kidney, ureter, and bladder (KUB) x-ray

Maximum number of patient were reported for radio opaque shadow in left kidney $(n=21,30.00 \%)$ and then right kidney $(n=15,21.43 \%)$.

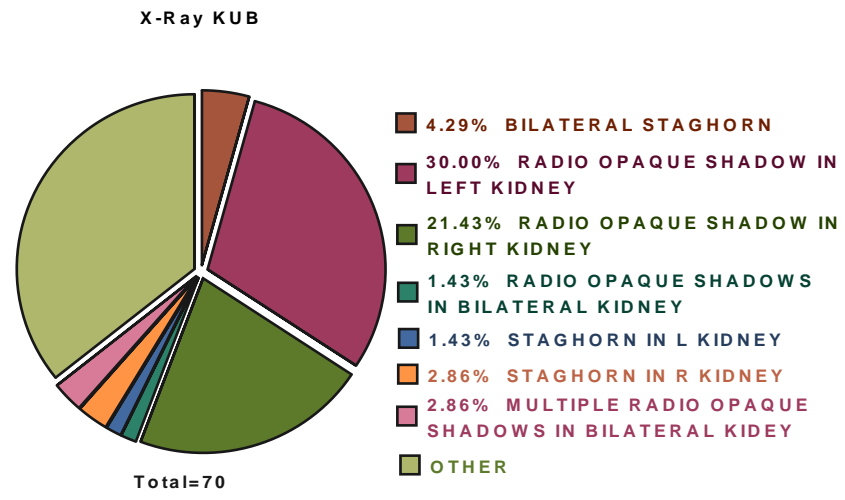

Figure 5: Kidney, ureter, and bladder (KUB) x-ray

\section{Blood biochemistry}

We reported high level of serum creatinine, serum calcium, and serum phosphorus level in the patients then the normal range of each parameter.

Table 4: Blood biochemistry

\begin{tabular}{|c|c|c|c|c|}
\hline $\begin{array}{c}\text { BLOOD } \\
\text { BIOCHEMISTRY }\end{array}$ & $\begin{array}{c}\text { Minimu } \\
\mathrm{m} \\
\text { value }\end{array}$ & $\begin{array}{c}\text { Maximu } \\
\mathrm{m} \\
\text { value }\end{array}$ & $\begin{array}{c}\text { Mean } \\
\text { value }\end{array}$ & $\begin{array}{c}\text { Std. } \\
\text { Deviatio } \\
\mathrm{n}\end{array}$ \\
\hline $\begin{array}{c}\text { BLOOD UREA } \\
(10-45 \mathrm{mg} / \mathrm{dl})\end{array}$ & 12.00 & 96.00 & 25.47 & 13.91 \\
\hline $\begin{array}{c}\text { CREATININE } \\
(0.6 \text { to } 1.3 \mathrm{mg} / \mathrm{dL})\end{array}$ & 0.7 & 5.40 & 1.36 & 0.84 \\
\hline $\begin{array}{c}\text { SERUM Ca } \\
(2.0-2.5 \mathrm{mmol} / \mathrm{L})\end{array}$ & 6.70 & 10.10 & 8.38 & 0.85 \\
\hline $\begin{array}{c}\text { SERUM P } \\
(0.81-1.29 \mathrm{mmol} / \mathrm{L})\end{array}$ & 1.90 & 2.60 & 2.29 & 0.17 \\
\hline $\begin{array}{c}\text { SERUM URIC ACID } \\
(2.4-7.2 \mathrm{mg} / \mathrm{dL})\end{array}$ & 4.90 & 7.00 & 5.72 & 0.53 \\
\hline SERUM Mg & 1.2 & 2.1 & 1.66 & 0.22 \\
\hline $\begin{array}{c}\text { SERUM Na } \\
(130-145 \mathrm{mEq} / \mathrm{L})\end{array}$ & 130.0 & 139.0 & 132.3 & 2.30 \\
\hline $\begin{array}{c}\text { SERUM K } \\
(3.5-5.5 \mathrm{mEq} / \mathrm{L})\end{array}$ & 4.00 & 5.20 & 4.52 & 0.45 \\
\hline
\end{tabular}

Urine biochemistry analysis

The mean values of urine test parameters were shown in below table. It is well known that the raised excretion of uric acid, calcium and phosphorus in the urine increase the formation of urolithiasis.

Table 5: Urine biochemistry analysis.

\begin{tabular}{|c|c|c|c|}
\hline URINE BIOCHEMISTRY & Minimum & Maximum & Mean \pm SD \\
\hline Urinary Calcium & 152.6 & 170.1 & $164.90 \pm 3.56$ \\
\hline Urinary Phosphorus & 447.9 & 459.1 & $453.4 \pm 3.09$ \\
\hline Urinary Uric Acid & 507.2 & 550.1 & $525.83 \pm 10.41$ \\
\hline
\end{tabular}

\section{Urine culture}

Calcium Oxalate Monohydrate content was found $63.99 \pm 16.05 \%$ in analysed stone. Acinetobacter, Enterococccus species, Escherichia Coli, Gram negative bacilli, Klebsiella pneumonia, Pseudomonas species and Trichosporon species were found in few patients. 


\section{International Journal of Science and Research (IJSR) \\ ISSN (Online): 2319-7064 \\ Index Copernicus Value (2013): 6.14 | Impact Factor (2015): 6.391}

Table 6: Urine culture analysis

\begin{tabular}{|c|c|c|}
\hline & Number of patients & $\%$ \\
\hline Acinetobacter & 1 & 0.7 \\
\hline Enterococccus species & 4 & 2.8 \\
\hline EscherichiaColi & 2 & 1.4 \\
\hline Gram negative bacilli & 1 & 0.7 \\
\hline Klebsiella pneumoniae & 2 & 1.4 \\
\hline Pseudomonas species & 3 & 2.1 \\
\hline Trichosporon species & 1 & 0.7 \\
\hline No Growth & 30 & 21 \\
\hline Not Done & 26 & 18.2 \\
\hline
\end{tabular}

\section{Stone composition}

Stone composition is the basis for further diagnostic and management decisions. Stones are often formed from a mixture of substances. Calcium oxalate monohydrate content was found $63.99 \pm 16.05 \%$ in analysed stone. Calcium dihydrate $(44.55 \pm 6.105)$, ammonium urate (28.24 \pm 10.74$)$ and calcium phosphate $(47.81 \pm 16.63)$ were present in the stone. Dicalcium phosphtate was present in 9 stones and carbon apatite was present in 10 stones.

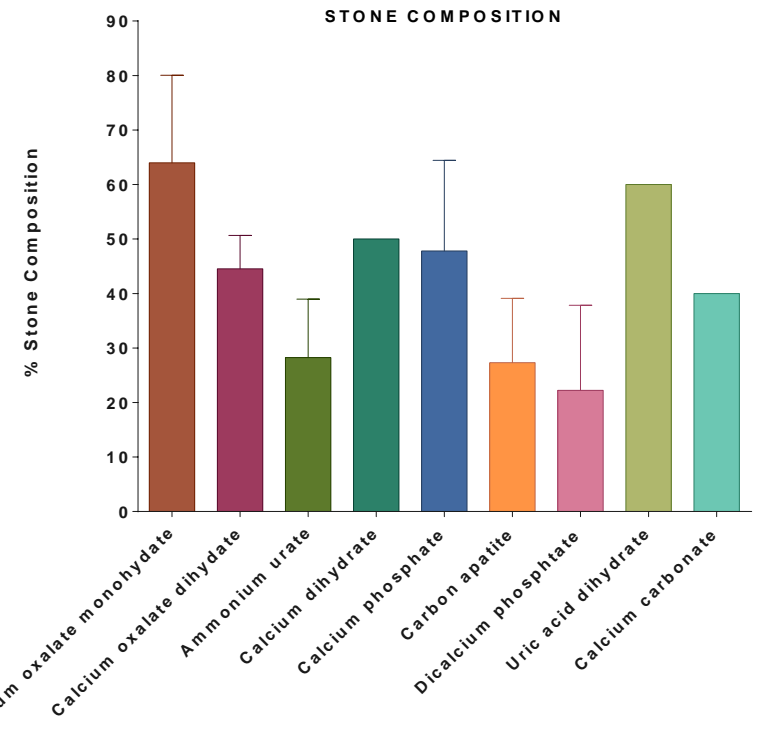

Figure 6: Stone composition.

\section{Discussion}

Kidney stones are a common problem worldwide with a marked increase in prevalence over the past 20 years. It is anticipated that there will be an increase in kidney stones in the future due to global warming, lifestyle changes, diet and obesity[21, 22]. The kidney stones are associated with increased rates of chronic kidney disease, hypertension and myocardial infarction [23-25].

\footnotetext{
Age

Several authors have demonstrated that lithiasis usually occurs between age 31-60 year of an individual's life[13, 26]. At international level, age at peak incidence was similar amongKorea, United States, and Japan,ranging from 40 to 49 years, except for Japanese women for whom the peak incidence occurred between ages 50 to 59 years.[27] The actual incidence rate was similar for men age 40 to 49 years in the United States and Japan but lower in Iran.[27] At national level,Durgawale et al (2010)[12] reported urolithiasis was more suffered by individuals between the
}

age group of 30 to 60 years in Karad, a South West region in Maharashtra (India). Kaur et al (2012)[13] observed that the highest incidence of renal stones in patients of Patiala, India was in the age group of 31-60 years.

This finding was in accordance with our study.In our study, we had taken 70 patients with the urolithiasis. Maximum number of patients $(n=26,37.14 \%)$ observed in the sixth decade (51-60 year) of their life. From age 31 to 60 year, were found total 54 patients which represent $77.14 \%$ of studied patients.

\section{Gender}

More men form stones than women. The sex ratios range from 2.5:1 in Japan to 1.15:1 in Iran.[28, 29]Durgawale et al (2010)[12] reported urolithiasis was more predominance in males than females. Kaur et al (2012)[13]reported incidence in males and females was in the ratio of 3.3:1. The prevalence of urolithiasis in male to female's ratio was 1.33:1 in our study.

\section{Pain due to urolithiasis}

The calculi may stay in the position in which they are formed, or migrate down the urinary tract, producing symptoms along the way.Pain and its location during urolithiasis is common and very patient to patient according to position of stone. Clinical manifestations are characterized by lumbar pain of sudden onset that may be accompanied by nausea and vomiting, gross or microscopic haematuria. In our study, we reported four main positions where patient feel flank pain is bilateral lumbar region, left lower abdomen, right lumber region and right side of abdomen. In our study most of patients had pain in left lower abdomen ( $n=31,44.29 \%)$ while equal number patient had pain in bilateral lumber region and right side of abdomen ( $n=14,20 \%$ each).Radiating back pain was observed in 47 patient, while only 23 patients were reportedabsence of radiating back pain. Sharma et al[30] (2014) reported majority of patients were admitted with the complaint of pain $(96.3 \%)$, and fever $(77.5 \%)$. In majority $(41.3 \%)$ of patients tenderness was present in Rt flank/ iliac fossa. Suprapubic tenderness was present in only $12.5 \%$ of cases. Among all patients who presented with pain, majority (87.5\%) of them showed pain radiation to back, groin or loin. Most of them were having unilateral pattern (60.0\%) and only few cases presented as bilateral pain. Approximately $10 \%$ patients of vesical calculi presented with supra-pubic pain.

\section{Urinary symptoms}

Symptoms like haematuria, burning micturition and increase frequency ofurination was observed in the recruited patients. These patients mostly present with acute episodes of pain and burning micturition. Haematuria is less common way of presentation here. Burning micturition was the commonest problem in patients $(n=31,44.29 \%)$. Haematuria was observed in 27 patients only. Increased frequency of urination was observed in 13 patients only. Sharma et al (2014)[30] reported that majority of patients were admitted with the complaint of burning micturition (85\%) and fever (77.5\%). $30 \%$ of patients had gross haematuria and around $11.25 \%$ of patients were admitted as acute retention of urine. 


\section{International Journal of Science and Research (IJSR) \\ ISSN (Online): 2319-7064 \\ Index Copernicus Value (2013): 6.14 | Impact Factor (2015): 6.391}

In the study conducted by Sepahi (2010)[31] the main clinical presentations were fever, pain, irritability, dysuria and haematuria which is also similar to the results obtained by the present study. In the study done by Ali[32], haematuria was present in $44.6 \%$ patients and pain in $28.4 \%$ patients.

\section{Type of drinking water}

Drinking water may be considered an extrinsic epidemiological factor. In our study, we found the most of the patients were drinking tap water $(n=53,75.71 \%)$ whilefew patients were drinking bore well water $(n=17$, 24.29\%).Caudarella et al(1998)[33] reported that mineral water with a higher calcium content induced increased calcium excretion but significantly decreased oxalate excretion in patients with idiopathiccalcium lithiasis. These data are in accordance with those of others, who did not find definite evidence that hard water is more lithogenic than soft water. Furthermore, water components other than calcium can modify the tendency toward crystal formation, affecting inhibitory power and/or lithogenic salt excretion. The wellwater is hard and contains many minerals. The sodium chloride concentration of well water remained very high. It has been reported that the recurrence of renal stones increased with the ingestion of hard water[34], and that people who drank water with a low $\mathrm{Mg} / \mathrm{Ca}$ ratio had a higher incidence of urinary stone disease in Japan[35]. Similarly, Yanagawa et al[36] reported that the patients who drank the well-water, which was similar in content to that in the Japanese study, tended to develop urinary stones, which confirms the finding of Kohri et al[35]. As compared with both tap and soft water, hard water was associated with a significant $50 \%$ increase of the urinary calcium concentration in the absence of changes of oxalate excretion; the calcium-citrate index revealed a significant threefold increase during ingestion of hard water as compared with respect to soft water, making the latter preferable even when compared with tap water.[37]Study suggests that, intake of soft water is preferable to hard water, since it is associated with a lower risk for recurrence of calcium stones.[37]

\section{X-rays of the kidney, ureter and bladder (KUB)}

Plain X-rays of the kidney, ureter and bladder (KUB) are useful in watching the passage of radio-opaque stones (around $75 \%$ of stones are of calcium and so will be radioopaque). In our study, maximum number of patient were reported for radio opaque shadow in left kidney $(n=27$, $38.57 \%)$ and then right kidney $(n=19,27.14 \%)$. It indicated the presence of calcium stone in patients.

\section{Blood and urine biochemistry}

The long-term intake of drinking water harder results in a higher local blood supply in the kidneys and subsequent adaptation of the filtration and reabsorption processes in the kidney. This is believed to be protective reaction of the human body which may lead, if the conditions persist, to alteration of the body's regulatory system with possible subsequent development of urolithiasis and hypertension.Most patients with stone disease have identifiable risk factors, it is worthwhile to evaluate for underlying causes of stone formation. The aetiology of renal stones is multifactorial; however, hypercalciuria is considered to be one of the primary risk factors.[38]In our study, we reported high level of serum calcium level in the patients then the normal range of each parameter. StarupLinde et al(2012)[39] reported that patients with renal calcification had lower plasma creatinine than patients without renal calcifications.

The 24-hour urine collection is the cornerstone of the evaluation of patients with renal stones as it allows for calculation of urinary super saturations for the various salts associated with lithogenesis such as calcium oxalate $(\mathrm{CaOx})$, calcium phosphate (CaP), and uric acid (UA), as well as the identification of specific metabolic derangements that may be contributing to risk. Schwartz et al (2002)[40] reported 24-hour urine calcium, magnesium, and citrate levels increased directly with drinking water hardness, and no significant change was found in urinary oxalate, uric acid, $\mathrm{pH}$, or volume.Uric acid is a weak organic acid with a $\mathrm{pKa}$ of 5.5. Therefore, at low urine $\mathrm{pH}$, undissociated uric acid precipitates to form uric acid stones[41]. Uric acid stones are increased in patients who have diarrheal illness[42], ileostomy[43], and metabolic syndrome[44]. Hivre et al (2013)[14]studiedurinary stone formation in an Aurangabad city of Maharashtra state, India. 24 hour urinary calcium in patients and control was $315 \pm 102.5$ and $255 \pm 175.3$ $(\mathrm{p}<0.03)$. Urinary phosphorus levels in patients with stones were higher compare to control $(190 \pm 112.3 \mathrm{v} / \mathrm{s} 182.5 \pm 115.5$, $\mathrm{p}=0.387)$. Urinary uric acid level was also higher (550.5 $\pm 265.3 \mathrm{v} / \mathrm{s} 480.6 \pm 310.5, \mathrm{p}=0.02)$. In conclusion, higher levels of urinary calcium was found in patients with urolithiasis in this subjects. Urine phosphorus levels were also statistically significant. In our study, urinary calcium

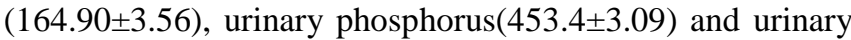
uric acid(525.83 \pm 10.41$)$ were higher than the normal range of individual levels.

\section{Stone composition}

Stone composition is the basis for further diagnostic and management decisions. Stones are often formed from a mixture of substances. In our study, we studied 141 stones by wet chemical analysis. Calcium oxalate were present in all stones. Phosphate was present in 58 stones and Ammonium acid urate was present in 10 stones. Calcium Oxalate Monohydrate content was found $61.50 \pm 17.14 \%$ in analysed stone. Calcium Dihydrate (36.67 \pm 15.28$)$,

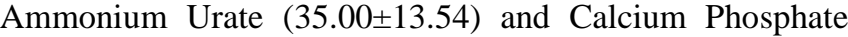
$(38.53 \pm 18.50)$ were equally present in the stone.

Renal calculi are formed when the urine is supersaturated with salt and minerals such as calcium oxalate, struvite (ammonium magnesium phosphate), uric acid and cystine. Approximately $80 \%$ of patients with nephrolithiasis form calcium stones, most of which are composed primarily of $\mathrm{CaOx}$ or, less often, $\mathrm{CaP}[45,46]$. In most cases, stone formation is associated with metabolic derangements that alter urine supersaturation for $\mathrm{CaOx}$ or $\mathrm{CaP}$, the most common of which is idiopathic hypercalciuria (IH)[47]. Hyperoxaluria, hypocitraturia, persistently elevated urine $\mathrm{pH}$, and increased urinary uric acid excretion can also increase risk of stone formation by raising supersaturation or decreasing the solubility of $\mathrm{CaOx}$ or $\mathrm{CaP}$ in urine.[48] Stones that contain more than 50\% CaP are uncommon[49]. The major determinants of CaP super saturation are alkaline urine $\mathrm{pH}$ (>6.3) combined with hypercalciuria[50]. Pure CaP 


\section{International Journal of Science and Research (IJSR) \\ ISSN (Online): 2319-7064 \\ Index Copernicus Value (2013): 6.14 | Impact Factor (2015): 6.391}

stones should always raise the possibility of an underlying defect in renal acid excretion.Shah et al (1991)[15]found that the common constituents of stones were calcium (98.7\%), oxalate $(87 \%)$, phosphate $(84.4 \%)$ and uric acid (76.6\%). Of all these, uric acid had the richest concentration in $93.2 \%$. Only 4 stones $(5.2 \%)$ were "pure": calcium oxalate-3 and calcium phosphate-1; whereas 73 (94.8\%) were mixed stones. Of these, $9(11.7 \%)$ were "predominant" mixed stones. The rest 64 (83.1\%) were "heterogeneous" mixed stones having rich concentration of more than one constituents.Bakane et al (1999)[3]found that calculi were mainly composed of calcium oxalate $(65.7 \%)$ and calcium phosphate (34.3\%).Singh et al (2001)[17] evaluated the role of fluoride in urolithiasis in humans for fluoride endemic area (EA) and a fluoride non-endemic area (NEA). Urinary stones from endemic patients had higher fluoride, oxalate and calcium levels than those from non-endemic patients. Durgawale et al (2010)[12] evaluated the stone composition in patients living inKarad, a South West region in Maharashtra (India). The chemical analysis of urolithiasis showed that all the assessed stones were of mixed heterogeneous type, Magnesium Ammonium Phosphate (71.2\%) was predominant constituent followed by Calcium Oxalate (68.8\%), Calcium Carbonate (64.0\%), Urate (44.8\%), Cystine (12.8\%), Xanthine (2.4\%) and Fibrin (1.6\%).Kaur et al (2012)[13] evaluated chemical constituents of renal stones in patients of Patiala, India. The chemical analysis of 94 renal stones showed that $90.4 \%$ of the analysed renal stones were of mixed type.

\section{Conclusion}

Our data through this study shows simple qualitative laboratory based method for assessing chemical composition of various urolithiasis allowed a reliable diagnosis of stone contents whose data may be useful in advising the patients of this region for taking preventive measures for reducing the risk of prevalence and recurrence of urolithiasis in them. The study concluded that it is important to know the chemical composition of stone as it is useful in advising people for taking preventive measures for reducing the risk of prevalence and recurrence can be considerably reduced by suitable reforms in diet and treatment regimen.

\section{References}

[1] Altaf, J., A.H. Arain, and N.L. Kella, Chemical Analysis of Urinary Stones and its Locations Associated to Urinary Tract. Journal of Liaquat University of Medical \& Health Sciences, 2013. 12(3): p. 203-207.

[2] Bartoletti, R., et al., Epidemiology and risk factors in urolithiasis. Urol Int, 2007. 79 Suppl 1: p. 3-7.

[3] Bakane, B.C., S.B. Nagtilak, and B. Patil, Urolithiasis : A tribal scenario. The Indian Journal of Pediatrics, 1999. 66(6): p. 863-865.

[4] Taylor, E. and G. Curhan, Fructose consumption and the risk of kidney stones. Kidney international, 2008. 73(2): p. 207-212.

[5] Knight, J., et al., Metabolism of fructose to oxalate and glycolate. Hormone and metabolic research= Hormonund Stoffwechselforschung $=$ Hormones et metabolisme, 2010. 42(12): p. 868.
[6] Johri, N., et al., An update and practical guide to renal stone management. Nephron Clinical Practice, 2010. 116(3): p. c159-c171.

[7] Vijaya, T., et al., Urolithiasis and Its Causes-Short Review. The Journal of Phytopharmacology, 2013. 2(3): p. 1-6.

[8] Singh, P., et al., Urolithiasis in Manipur (north eastern region of India). Incidence and chemical composition of stones. The American journal of clinical nutrition, 1978. 31(9): p. 1519-1525.

[9] Pendse, A.K. and P.P. Singh, The etiology of urolithiasis in udaipur (Western Part of India). Urological Research, 1986. 14(2): p. 59-62.

[10] Hussain, F., F.R. Billimoria, and P.P. Singh, Urolithiasis in Northeast Bombay: Seasonal prevalence and chemical composition of stones. International Urology and Nephrology, 1990. 22(2): p. 119-124.

[11] Sarada, B. and U. Satyanarayana, Urinary composition in men and women and the risk of urolithiasis. Clinical Biochemistry, 1991. 24(6): p. 487-490.

[12] Durgawale, P., et al., Chemical analysis of stones and its significance in urolithiasis. Biomedical Research, 2010. 21(3): p. 305-310.

[13] Kaur, H., et al., Analysis of biochemical profile of renal stones referred to advanced Biochemistry laboratory of a multispecialty tertiary care Hospital in Punjab. European Journal of Experimental Biology, 2012. 2(3): p. 543-546.

[14] Hivre MD, B.D., Bujurge AA, Mahat RK., A Study of 24 Hour Urinary Calcium, Phosphorus and Uric Acid Levels in Normal Subjects and Patients with Urolithiasis. International Journal of Recent Trends in Science And Technology, 2013. 9(2): p. 197-198.

[15] Shah, A., et al., Spectrum of pediatric urolithiasis in western India. The Indian Journal of Pediatrics, 1991. 58(4): p. 543-549.

[16] Heneghan, J.P., et al., Helical CT for Nephrolithiasis and Ureterolithiasis: Comparison of Conventional and Reduced Radiation-Dose Techniques 1. Radiology, 2003. 229(2): p. 575-580.

[17] Singh, P.P., et al., Evidence suggesting that high intake of fluoride provokes nephrolithiasis in tribal populations. Urol Res, 2001. 29(4): p. 238-44.

[18] Tamm, E.P., P.M. Silverman, and W.P. Shuman, Evaluation of the Patient with Flank Pain and Possible Ureteral Calculus 1. Radiology, 2003. 228(2): p. 319329.

[19] Milicevic, S., R. Bijelic, and B. Jakovljevic, Correlation of Parathormone and the Serum Values of Acidum Uricum with Calcium Nephrolithiasis Examined by Three Different Methods of Diagnostics. Acta Informatica Medica, 2015. 23(3): p. 132.

[20] Bhale DV, H.M., Mahat RK. Bujurge AA., Study of Serum Calcium, Phosphorus and Uric Acid Levels in Patients of Urinary Calculi. International Journal of Recent Trends in Science And Technology, 2013. 9(2): p. 189-190.

[21] Romero, V., H. Akpinar, and D.G. Assimos, Kidney stones: a global picture of prevalence, incidence, and associated risk factors. Reviews in urology, 2010. 12(2-3): p. e86. 


\section{International Journal of Science and Research (IJSR) \\ ISSN (Online): 2319-7064 \\ Index Copernicus Value (2013): 6.14 | Impact Factor (2015): 6.391}

[22] Taylor, E.N., M.J. Stampfer, and G.C. Curhan, Obesity, weight gain, and the risk of kidney stones. Jama, 2005. 293(4): p. 455-462.

[23] Rule, A.D., et al., Kidney stones and the risk for chronic kidney disease. Clinical Journal of the American Society of Nephrology, 2009. 4(4): p. 804811.

[24] Madore, F., et al., Nephrolithiasis and risk of hypertension. American journal of hypertension, 1998. 11(1): p. 46-53.

[25] Rule, A.D., et al., Kidney stones associate with increased risk for myocardial infarction. Journal of the American Society of Nephrology, 2010. 21(10): p. 1641-1644.

[26] Rotolo, J., W. O'Brien, and J. Pahira, Urinary tract calculi. Part I: newer insights into the causes of stone formation. Consultant, 1989. 29: p. 129-133.

[27] Romero, V., H. Akpinar, and D.G. Assimos, Kidney stones: a global picture of prevalence, incidence, and associated risk factors. Rev Urol, 2010. 12(2-3): p. e86-96.

[28] Safarinejad, M.R., Adult urolithiasis in a populationbased study in Iran: prevalence, incidence, and associated risk factors. Urological research, 2007. 35(2): p. 73-82.

[29] Fujita, K., Epidemiology of urinary stone colic. European urology, 1978. 5(1): p. 26-28.

[30] Sharma, G.R., et al., Clinical presentations of urolithiasis: a prospective study in Referral Centre. Pain. 77: p. 96.3.

[31] Sepahi, M.A., A. Heidari, and A. Shajari, Clinical manifestations and etiology of renal stones in children less than 14 years age. Saudi Journal of Kidney Diseases and Transplantation, 2010. 21(1): p. 181.

[32] Ali, S.H. and U.N. Rifat, Etiological and clinical patterns of childhood urolithiasis in Iraq. Pediatric Nephrology, 2005. 20(10): p. 1453-1457.

[33] Caudarella, R., et al., COMPARATIVE STUDY OF THE INFLUENCE OF 3 TYPES OF MINERAL WATER IN PATIENTS WITH IDIOPATHIC CALCIUM LITHIASIS. The Journal of Urology, 1998. 159(3): p. 658-663.

[34] Popovtzer, M., et al., Kidney stones and drinking water. The New England journal of medicine, 1984. 310(11): p. 721.

[35] Kohri, K., et al., Magnesium-to-calcium ratio in tap water, and its relationship to geological features and the incidence of calcium-containing urinary stones. The Journal of urology, 1989. 142(5): p. 1272-1275.

[36] Yanagawa, M., et al., Incidence of urolithiasis in northeast Thailand. International journal of urology, 1997. 4(6): p. 537-540.

[37] Bellizzi, V., et al., Effects of water hardness on urinary risk factors for kidney stones in patients with idiopathic nephrolithiasis. Nephron, 1999. 81 Suppl 1: p. 66-70.

[38] Park, S. and M.S. Pearle, Pathophysiology and management of calcium stones. Urologic Clinics of North America, 2007. 34(3): p. 323-334.

[39] Starup-Linde, J., et al., Renal stones and calcifications in patients with primary hyperparathyroidism: associations with biochemical variables. European Journal of Endocrinology, 2012. 166(6): p. 1093-1100.
[40] Schwartz, B.F., et al., Calcium nephrolithiasis: effect of water hardness on urinary electrolytes. Urology, 2002. 60(1): p. 23-27.

[41] Sakhaee, K., et al., Pathophysiologic basis for normouricosuric uric acid nephrolithiasis. Kidney international, 2002. 62(3): p. 971-979.

[42] Parks, J.H., et al., Urine stone risk factors in nephrolithiasis patients with and without bowel disease. Kidney international, 2003. 63(1): p. 255-265.

[43] Clarke, A. and R. McKenzie, Ileostomy and the risk of urinary uric acid stones. The Lancet, 1969. 294(7617): p. 395-397.

[44] Abate, N., et al., The metabolic syndrome and uric acid nephrolithiasis: novel features of renal manifestation of insulin resistance. Kidney international, 2004. 65(2): p. 386-392.

[45] Johnson, C.M., et al., Renal stone epidemiology: a 25year study in Rochester, Minnesota. Kidney Int, 1979. 16(5): p. 624-631.

[46] Coe, F.L., J.H. Parks, and J.R. Asplin, The pathogenesis and treatment of kidney stones. New England Journal of Medicine, 1992. 327(16): p. 11411152.

[47] Worcester, E.M. and F.L. Coe. New insights into the pathogenesis of idiopathic hypercalciuria. in Seminars in nephrology. 2008. Elsevier.

[48] Xu, H., et al., KIDNEY STONES: AN UPDATE ON CURRENT PHARMACOLOGICAL MANAGEMENT AND FUTURE DIRECTIONS. Expert opinion on pharmacotherapy, 2013. 14(4): p. 435-447.

[49] Coe, F.L., J.H. Parks, and J.R. Asplin, The pathogenesis and treatment of kidney stones. $\mathrm{N}$ Engl J Med, 1992. 327(16): p. 1141-52.

[50] Parks, J.H., et al., Clinical implications of abundant calcium phosphatein routinely analyzed kidney stones. Kidney international, 2004. 66(2): p. 777-785. 